\title{
Pilot Chargeback System Program Plan
}

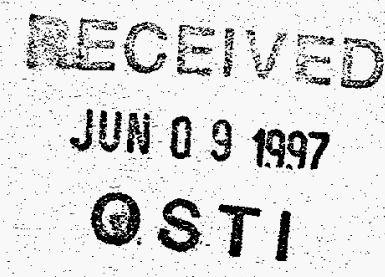

P. Smith

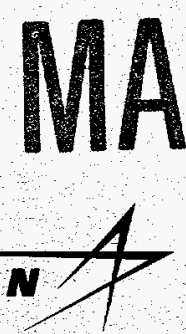




\section{DISCLAMMIRR}

Portions of this document may be illegible in electronic image products. Images are produced from the best available original document. 


\title{
Pilot Chargeback System Program Plan
}

\author{
P. Smith
}

Published March 1997

Idaho National Engineering Laboratory

Waste Technology Planning and Project Department

Lockheed Martin Idaho Technologies Company

Idaho Falls, Idaho 83415

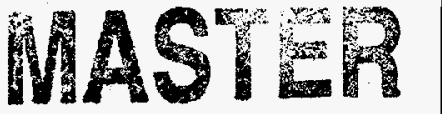

DISTRIBUTION OF THIS DOCUMENT IS UNLIMTTED

Prepared for the

U.S. Department of Energy

Assistant Secretary for Environmental Management

Under DOE Idaho Operations Office

Contract DE-AC07-94ID13223 


\section{PILOT CHARGEBACK SYSTEM PROGRAM PLAN}

\section{Introduction/Justification}

a. Purpose. This planning document outlines the steps necessary to develop, test, evaluate, and potentially implement a pilot chargeback system at the Idaho National Engineering and Environmental Laboratory (INEEL) for the treatment, storage, and disposal of "current" waste. The implementation plan provides details on how these plans will be executed. This pilot program will demonstrate one system that the Department of Energy (DOE) could use to charge generators for the treatment and disposal of low-level radioactive waste (LLW).

It is anticipated that implementing such a system will result in benefits such as reduced generation rates, reduced management costs, increased management options, improved waste forecasts, "cradle-to-grave" accountability, and clear lines of responsibilities.

b. History. Currently, DOE-HQ is working a Waste Management Re-Engineering Initiative that includes pilot testing alternative strategies for transitioning the management and funding responsibility for various waste types. This initiative is driven largely by the recommendations of several advisory groups, including the National Research Council, The Environmental Management Advisory Board, the Waste Management Alternatives Working Group, and an Independent Technical Review (the Red Team).

Chargeback is not a new concept at the INEEL. In the last three years, two previous attempts to extend this concept to onsite generators were halted because of institutional issues at the HQ and Congressional levels. HQ has worked these issues with Congress and believes it has the support necessary to test the concept on a pilot basis prior to full, Complex-wide implementation. Insights gained in these previous efforts and the continuing work at other DOE field offices will be used in the INEEL pilot project.

c. Overview. In FY 1997, mock billings will begin by July 15, 1997. Assuming approvals are received to do so, FY 1998 activities will include modifying the associated automated systems, testing and evaluating system performance, and estimating the amount generators will spend for waste storage, treatment, and disposal in FY 1999. If the program is fully implemented in FY 1999, generators will pay actual, automated bills for waste management services from funds transferred to their budgets from Environmental Management.

\section{Project Strategy}

a. Strategy. The INEEL chargeback system will be based on the results of the work done previously. This information will be modified to accommodate direction from DOE, current issues and concerns raised by the chargeback working group, and the approaches used at 
other DOE field offices. It is believed that such a strategy will strengthen the credibility and the underpinnings of the INEEL chargeback system.

b. Actions. Although numerous activities are needed to complete this process, the following represent the major steps that must be accomplished to successfully plan, develop, test, evaluate, and implement the pilot chargeback system.

\section{$\underline{\text { FY } 1997}$}

- Complete an implementation plan. The implementation plan will provide the details of how the chargeback program will be accomplished.

- Determine the costs to be recovered by the chargeback system. These costs will be determined by dividing all budgeted waste management costs between programmatic and non-programmatic activities. Waste generators will pay the non-programmatic costs using the chargeback system. Programs will be responsible to pay all programmatic costs.

- Make waste shipping projections. These projections form the basis for planning disposal operations. Variances between actual and projected waste shipments will be resolved using processes established by the working group.

- Establish waste management fees. Fee rates will be determined and published for contact handled and remote-handled LLW by taking into account their projected volumes and their total non-programmatic management costs.

- Begin mock billings. A system for charging waste generators the cost of managing their waste will be developed. In FY 1997, this system will be only partially automated. It is anticipated that approval will be given to completely automate the system in FY 1998. This system will use the established fee schedule to calculate the cost for managing all LLW shipped and send the bill to the waste shipper or generator.

- Receive approval for FY 1998 activities. Planned FY 1998 activities include evaluating and modifying the chargeback system and its associated automated systems, preparing a report documenting the operational readiness of the system, and estimating the amounts that Environmental Management will transfer to generator budgets in FY 1999.

- Establish evaluation criteria for the pilot program. The working group will be instrumental in determining the criteria for evaluating how well the chargeback system is working. 


\section{$\underline{\text { FY } 1998}$}

Assuming the FY 1997 pilot project is successful and HQ continues its support, the following activities would take place in FY 1998:

- Estimate funds for Environmental Management transfers to generator budgets. These funds are to pay all generator waste management costs in FY 1999 but will only become effective if the decision is made at DOE to implement the system.

- Periodically, liquidate the chargeback account. Periodic liquidations of the chargeback account are designed to resolve differences between expected costs and revenues and could be done either on a timed schedule or when preset limits are exceeded. Procedures for accomplishing this task will be explained in the implementation plan.

- Identify and implement changes to the chargeback program and automated systems. Based on periodic evaluations of the system by the working group, changes will be made, as appropriate, to its processes and the automated systems. All changes will be documented.

- Prepare an operational readiness report. This report is designed to capture the operating history of the system and an evaluation of how well the system is meeting its established objectives.

\section{FY 1999}

- Begin actual, automated billings. This will only occur if DOE decides to implement the system.

c. Evaluation. If it is decided to continue the pilot in FY 1998, evaluation criteria will be developed by the chargeback working group with input from others representing affected INEEL organizations. The èvaluation process will not be performed until sufficient information has been gathered through the mock billing system to allow the team to judge the system against the criteria.

\section{Work Scope}

a. End Objective. The final objective is to complete all activities necessary to implement the INEEL chargeback system in FY 1999. Accomplishing this objective is contingent upon receiving approval from DOE in FY 1998 to continue the pilot program or implement the full chargeback program once sufficient operational experience has been collected to make the decision. 
b. Deliverables and Due Dates. This identifies the key deliverables and expected completion dates for full implementation of the chargeback system. This is subject to change based upon changes in requirements, assumptions, or other direction from DOE.

Chargeback Program Plan

Initial Mock Billings

Operational Readiness Report
$3 / 31 / 97$

$7 / 15 / 97$

$8 / 31 / 98$

c. Requirements. This list represents the major constraints that the INEEL chargeback program must operate within or conditions that must be met for it to go forward. The list is based on DOE guidance and other conditions identified by the chargeback working group, but excludes deliverables and due dates.

- No modifications to automated systems will be performed in FY 1997.

- All chargeback activities will be conducted in accordance with current rules, regulations, and guidance.

d. Assumptions. The assumptions underlying the INEEL chargeback program are provided below. Changes to these assumptions could affect how the program is structured, planned, tested, and evaluated.

- Adequate data will be available to complete the development of unit charge rates.

- FY 1998 activities and funding are approved.

- Access is allowed to perform all necessary modifications to the automated systems.

- HQ and the Congressional Budget Office find solutions to current financial constraints.

- The need for consistency between sites will not negatively impact the INEEL chargeback approach or schedule.

e. Funding. It is estimated that $\$ 84.7 \mathrm{~K}$ will be needed for FY 1997 and approximately $\$ 100 \mathrm{~K}$ in FY 1998 to accomplish the activities outlined in this program plan.

\section{Chargeback Participants}

a. Program Management. Development of the chargeback system is the responsibility of the chargeback program manager. The program manager reports to DOE and LMITCO management. 
b. Chargeback Working Group. The chargeback working group is responsible for providing insight and guidance to the program manager on how to develop the chargeback system within the constraints of DOE and LMITCO management. The members of the working group are drawn from organizations that will be affected by the chargeback system and are expected to reflect the concerns and ideas of their organizations. Incorporation of recommendations made by the chargeback working group are made at the discretion of the program manager. 